\title{
Pierre Buvat, Sur les pas de George Sand au pays du rêve
}

Annarosa Poli

\section{Q OpenEdition}

1 Journals

\section{Edizione digitale}

URL: https://journals.openedition.org/studifrancesi/40957

DOI: 10.4000/studifrancesi.40957

ISSN: 2421-5856

\section{Editore}

Rosenberg \& Sellier

\section{Edizione cartacea}

Data di pubblicazione: 1 juillet 2004

Paginazione: 211-212

ISSN: 0039-2944

\section{Notizia bibliografica digitale}

Annarosa Poli, «Pierre Buvat, Sur les pas de George Sand au pays du rêve», Studi Francesi [Online], 142

(XLVIII | I) | 2004, online dal 30 novembre 2015, consultato il 09 septembre 2021. URL: http:// journals.openedition.org/studifrancesi/40957; DOI: https://doi.org/10.4000/studifrancesi.40957

Questo documento è stato generato automaticamente il 9 septembre 2021.

\section{(c) (i) (9)}

Studi Francesi è distribuita con Licenza Creative Commons Attribuzione - Non commerciale - Non opere derivate 4.0 Internazionale. 


\title{
Pierre Buvat, Sur les pas de George Sand au pays du rêve
}

\author{
Annarosa Poli
}

\section{NOTIZIA}

PIERRE BUVAT, Sur les pas de George Sand au pays du rêve, chez l'auteur, 23220 Chambon-

Sainte-Croix, 2000, album de 26 planches illustrées, pp. 212.

P.Buvat termina con questa opera la trilogia che ha dedicato a George Sand.

Ogni album è composto da 26 fogli classificati dalla A alla Z .

Il primo volume, edito nel 1995 (prefazione di Jean мІот), è ormai esaurito. La prosa si alternava a disegni per presentare Nohant, i giardini, i castelli, i sentieri pittoreschi del Berry e della Marche.

4 Il secondo volume del 1999 con prefazione di Françoise CHANDERMAYOR, illustrava gli itinerari e i luoghi descritti da George Sand nella Francia e nell'Europa dell'Ottocento da Guillery a Lugano, da Maiorca alle Ardenne, da Venezia a Caux passando per la Svizzera e non trascurando i domicili parigini della scrittrice.

5 Il terzo e ultimo volume si sofferma particolarmente sul tema del sogno, sui personaggi e paesaggi reali o mitici immaginati da George Sand. Ci si stupisce di alcune descrizioni e delle atmosfere di paesi che non aveva mai visitato, ma conosciuto attraverso disegni e illustrazioni.Capita poi -aggiungiamo noi- che sia molto meno attenta ai particolari di paesi in cui aveva realmente soggiornato.

6 Nel suo Avant propos l'A. ci lascia supporre le difficoltà di questa sua coraggiosa impresa: "Pour toutes ces évasions, afin de bien assister sa démarche, George Sand s'est documentée sérieusement.

7 J'ai dû en faire autant pour concevoir mes illustrations. S'il s'agit le plus souvent de fréquenter des pays géographiquement vrais, il arrive que notre romancière construise 
un décor entièrement imaginé, sans doute pour mieux aller vers le merveilleux ou l'idéal «.

8 Per gli appassionati ammiratori della scrittrice francese e per i bibliofili questi tre volumi costituiscono un contributo originale e poetico attraverso parola e immagine, per fare un viaggio letterario che ci aiuta a penetrare nell'intimo della scrittura sandiana. 